\title{
Algunas reflexiones acerca de las prácticas y representaciones sociales en estudiantes universitarios: la escritura académica
}

\author{
Lic. Ana María Bocca' \\ anabocca@hotmail.com
}

Lic. Nélida Beatriz Vasconcelo ${ }^{2}$

beatrizvasconcelo@yahoo.com.ar

\section{RESUMEN}

Los docentes universitarios nos enfrentamos con serias falencias en la lectura y escritura de textos académicos de los alumnos. Año tras año los resultados obtenidos por los ingresantes a las universidades argentinas avivan tanto en Tos ámbitos académicos como en los medios de comunicación la polémica acerca de la inadecuada formación lingüística con la que éstos egresan de la escuela media. Somos conscientes de que el alumno universitario debe desarrollar estrategias especiales para encarar sus prácticas lectoras y también es necesario que adquiera habilidades para la producción de textos académicos.

\section{Palabras clave}

Escritura académica, prácticas y representaciones sociales, lectura académica, dificultades, estrategias.

\section{ABSTRACt}

University professors are facing the fact that college students have serious difficulties with their reading and writing of academic texts. Year after year, the students' poor performance on college entrance exams in Argentina, due to the inadequate linguistic training they have when they graduate from high school, is subject of controversy within the academic field as well as in the media. We are well aware that college students need to develop special strategies and skills in order to understand and write academic texts.

\section{KEYWORDS}

Academic writing, practice and social representations, academic reading, difficulties, strategies.

1 Profesora en Lengua, Literatura y Latín para la Enseñanza Superior. Profesora titular de Gramática del Texto Español y Principios de Contrastividad. Profesora jefe de trabajos prácticos de Lengua Castellana I, Facultad de Lenguas, Universidad Nacional de Córdoba, Argentina. DNI: 6132632. "La escritura académica: prácticas y representaciones sociales en producciones de alumnos universitarios”, en: Secretaría de Ciencia y Técnica (SECyT).

2 Profesora titular de Didáctica del Español como Lengua Materna y ele. Profesora titular del taller Comprensión y Producción lingüísticas III, Facultad de Lenguas, Universidad Nacional de Córdoba, Argentina. Licenciada y profesora en Literaturas Modernas. DNI: 5181984. "La escritura académica: prácticas y representaciones sociales en producciones de alumnos universitarios”, en: Secretaría de Ciencia y Técnica (SECyT). 


\section{Introducción}

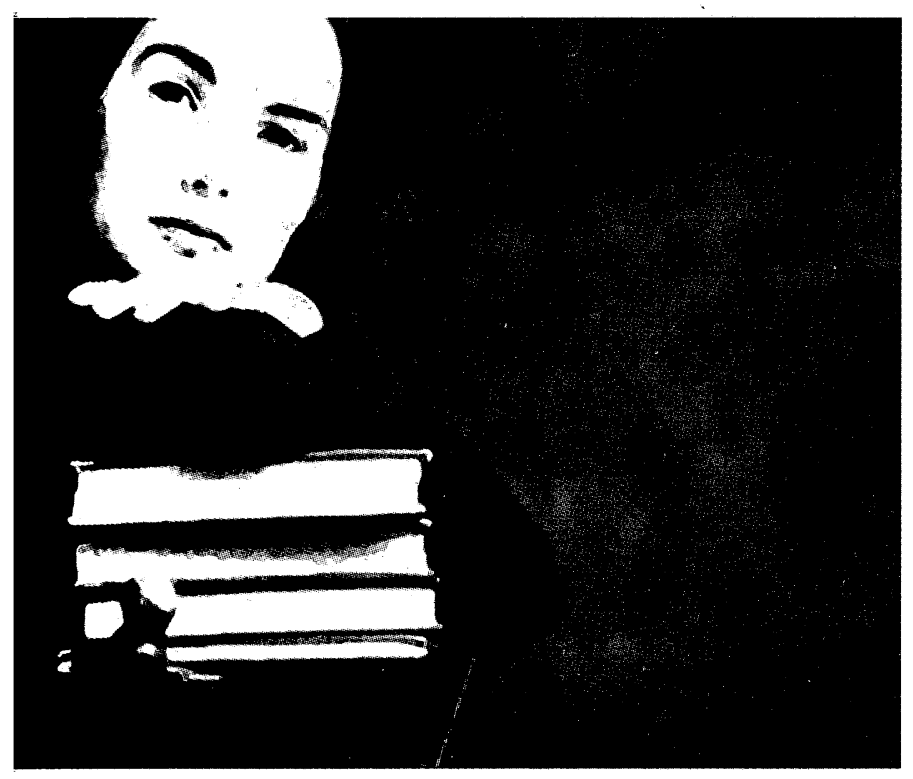

$\mathrm{E}$ 1 presente trabajo forma parte de un proyecto de investigación que estamos realizando en la Facultad de Lenguas de la Universidad de Córdoba, Argentina titulado "La escritura académica: prácticas y representaciones sociales en producciones de alumnos universitarios" (sесут) y dirigido por la licenciada Silvia Sosa de Montyn. Este proyecto intenta encauzar intereses de un grupo de profesores de Lengua Española de la Facultad preocupados por las falencias detectadas en el desempeño por parte de los estudiantes, tanto en la comprensión como en la producción de textos escritos.

Año tras año, los malos resultados obtenidos por quienes ingresan a nuestras universidades avivan no sólo en los ámbitos académicos, sino también en los medios de comunicación, la polémica acerca de la deficiente formación lingüística con la que éstos egresan de la escuela secundaria. Sin embargo, debemos preguntarnos qué hacemos los profesores universitarios para solucionar estos problemas y qué representaciones tenemos nosotros sobre la escritura académica y la enseñanza de ésta en la universidad. Muchos docentes creen que el nivel superior no debe enseñar a escribir, que es suficiente con lo que los alumnos han aprendido en los niveles anteriores, sin embargo la práctica de la escritura debe ser tan importante en este nivel como en los anteriores, ya que los textos que éstos deben producir tienen propósitos e intenciones diferentes

La escritura universitaria desempeña un papel primordial en la adquisición de nuevos conocimientos, además de encontrarse estrechamente relacionada con la lectura. Somos conscientes de que el alumno debe desarrollar estrategias especiales para encarar las prácticas lectoras y de que también es necesario que adquiera habilidades para la producción de textos académicos, pues éstos van adquiriendo rasgos que los hacen más complejos. Coincidimos con Elvira Arnoux cuando expresa que "ser un escritor eficiente de este tipo de textos implica en primer lugar ser un buen lector de textos académicos ya que en ese ámbito la mayor parte de los escritos se apoya en lecturas previas de las que necesariamente tendrá que dar cuenta" (Arnoux, 2005: 37).

Dentro de este marco es que se justifica un estudio pormenorizado sobre los procesos de comprensión y producción de la población estudiantil de las distintas carreras de nuestra $\mathrm{Fa}^{-}$ cultad, centrado en los dos primeros años y en el último curso de las carreras de Lenguas Extranjeras. La elección se debe a que en aquéllos se produce un mayor desgranamiento y a que en el último año se pueden constatar los avances e identificar las dificultades que todavía perviven en el desempeño como escritor.

Este estudio se centra en dos ejes:

- El análisis de las producciones escritas en español por los alumnos de $1^{\circ}, 2^{\circ}$ y $5^{\circ}$ años de las carreras de Inglés, Francés, Italiano, Portugués y Alemán para detectar las dificultades que se les presenta al momento de escribir textos. Específicamente, se analizarán producciones inherentes a los estudios de grado que suponen la lectura de una fuente bibliográfica pautada por la institución con la finalidad de explicar, informar y argumentar, entre otras tareas habituales de una clase.

- La indagación sobre las representaciones sociales respecto de las prácticas de escritura que poseen para así establecer asociaciones entre las concepciones relevadas y las dificultades detectadas. 
El objetivo general es analizar discursos académicos de alumnos en situaciones naturales de clase para identificar dificultades en relación con una tarea de escritura requerida y-las representaciones sociales que sobre esas prácticas poseen, y la relación que establecen entre escritura y lectura.

Compartimos la opinión de Paula Carlino cuando habla de

la necesidad de abandonar el modelo didáctico centrado en la mera transmisión de los conocimientos por parte del docente y que sea el alumno el verdadero protagonista de su aprendizaje y establecer propuestas para que éste tenga que desplegar una actividad intelectual mayor que la mera escucha de las clases magistrales y enseñarles uno de los saberes más valiosos que es la forma de aprender, de pensar, de indagar y además transmitirles los modos relacionados con la manera de leer y escribir de la comunidad académica a la cual pertenece (2005: 13).

El objetivo de este trabajo es presentar resultados de la primera etapa de esta investigación desde una perspectiva cualitativa; para ello hemos seleccionado los ítems de la encuesta realizada que se refiere a la concepción de la lectura y escritura académica: "qué significa escribir bien", "para qué leer y escribir" y "qué leen y escriben en la carrera", selección que nos permite conocer las

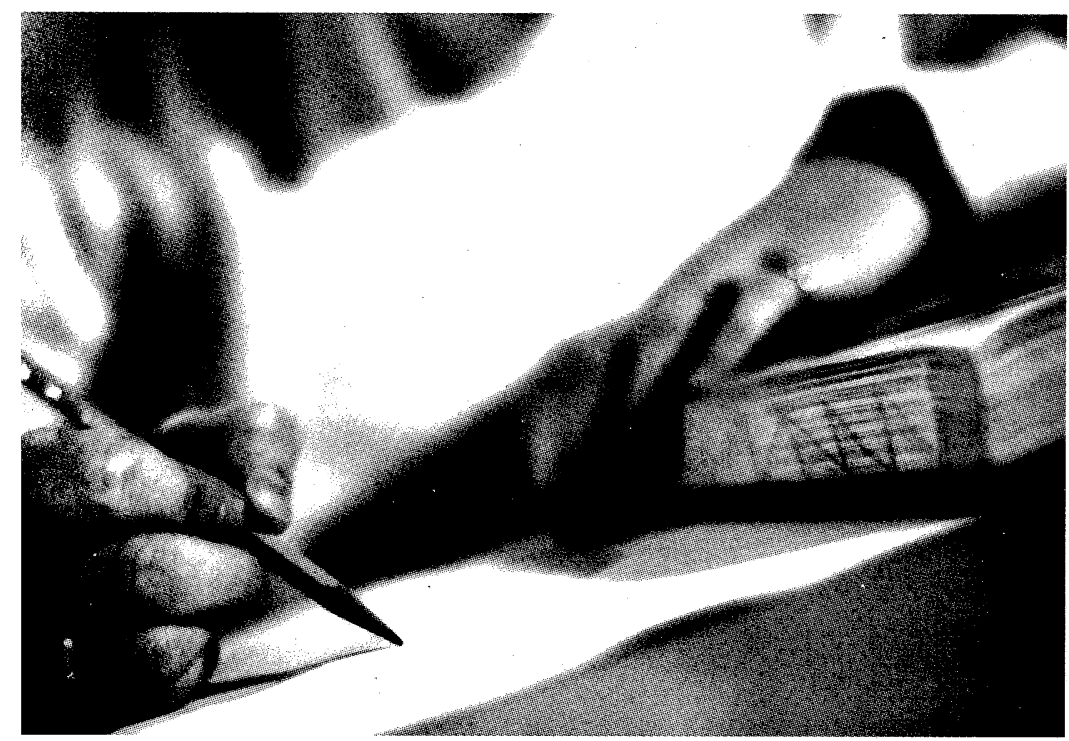

representaciones que los alumnos poseen de sus prácticas e interpretar sus dificultades. De este modo se podrán implementar estrategias de enseñanza que superen los obstáculos.

\section{Marco teórico}

El marco teórico en que se inscribe esta investigación parte de una perspectiva psicosociocognitiva. En los últimos años se ha desarrollado, en el mencionado campo de la investigación, un creciente interés por integrar datos que provienen de estos enfoques con "la intención, por un lado, de enfatizar las relaciones dialécticas entre el contexto sociocultural y los textos y, por otro lado, enfatizar las diversas características del proceso cognitivo que siguieron los estudiantes [...]" (Castello Badia, 2000: 69).

Escribir no es una actividad simplemente motriz, es una actividad intelectual que involucra una serie de reflexiones y operaciones mentales que constituyen una sobrecarga cognitiva que el escritor debe procesar. La escritura es un proceso en el que se van produciendo diferentes subprocesos mentales a través de los cuales el que escribe lleva a cabo diversas operaciones como la activación y recuperación de conocimientos previos, la elaboración de una idea, una representación del destinatario y la planificación de.su escrito. El escritor elabora un texto para probables lectores procurando satisfacer sus expectativas generales como también sus propias expectativas y compartiendo a su vez "una red de significados y representaciones" (Marinkovich Ravena, 1999: 31).

Desde esta visión, los lectores y los escritores van construyendo el significado del texto en respuesta a un problema; sin embargo, se hallan condicionados por un grupo de factores que no sólo provienen del proceso mismo de la escritura sino también del contexto sociocultural. "Cuando planeamos escribir, se crea una representación mental personal que incluye asociaciones, cosas que no podemos decir, palabras claves [sic], imágenes, sentimientos, etc. Cuando se expresa esa representación en lenguaje escrito, estamos componiendo una nueva y diferente representación del significado" (Marinkovich Ravena, 1999: 32). 
En el proceso cognitivo que se lleva a cabo en là escritura se pone en juego una amplia gama de conocimientos lingüísticos: el escritor debe decidir y elegir entre los distintos géneros discursivos, una organización sintáctica de las oraciones, la progresión temática, un léxico apropiado y el uso de convenciones ortográficas. La elección de estos aspectos tiene como finalidad producir un texto tan eficaz que el lector pueda fácilmente reconstruir los sentidos que el autor quiso comunicar. "Tanto el lector como el escritor convergen hacia el texto que los mediatiza y, en ese acto, ambos concurren con sus categorías cognitivas, metacognitivas, sociales y afectivas". (Marinkovich Ravena, 1999: 32).

En resumen, estamos en presencia de una visión interactiva de la escritura, tarea que no sólo involucra un proceso cognitivo y el uso del código lingüístico sino también el contexto. Esto quiere decir que todo texto tiene que ver con los mundos sociales en los que se produce.

\section{Metodología de análisis y descripción del corpus}

Una de las opciones metodológicas que abarca esta investigación se centra en las representaciones sociales (Rs) de escritura que los estudiantes construyen en torno a sus prácticas. Éstas son ampliamente investigadas a partir de los años 80, cuando se comienzan a generalizar los estudios sobre las Rs y a establecer un campo generalizado de su uso.

La teoría de las representaciones sociales ha recibido aportes de diferentes autores y disciplinas. Para Jodelet (1993) el concepto de RS involucra lo psicológico o cognitivo y lo social, y fundamenta que el conocimiento se constituye a partir de las experiencias propias de cada persona y de los modelos y las informaciones que reciben a través de la sociedad. Visto desde esta perspectiva, las Rs aparecen como un proceso de elaboración mental e individual en el que se considera la historia de la persona, la experiencia y sus construcciones propiamente cognitivas (Banch, 1991).

La dimensión representaciones sociales de escritura es entendida como el conjunto de "enunciados verbales [...] descriptibles y diferenciados producidos por actores sociales como formas de percepción y simbolización

de aspectos claves de la experiencia social" (Mato, 1999: 53).

En este trabajo consideramos que las representaciones sociales de escritura son sistemas interpretativos que pueden generar actitudes frente a la escritura, siempre interrelacionadas con la lectura, y orientadas hacia sus prácticas y relaciones contextuales. La utilidad didáctica de las representaciones sociales reside según Reuter (1996) en que ellas se asocian con el rendimiento, pueden constituir ayudas para el aprendizaje o bien ser obstáculo, y son modificables.

La población seleccionada para esta investigación está conformada por, aproximadamente, 300 alumnos de ambos sexos que cursan las materias Lengua Castellana I y II de $1^{\circ}$ y $2^{\circ}$ año correspondiente a todos los idiomas y de los cursantes de Metodología de la Investigación Lingüística de $5^{\circ}$ año, materia común a los distintos profesorados. Los estudiantes provienen de diferentes provincias argentinas, aunque el porcentaje mayor pertenece a la provincia de Córdoba. La edad de éstos oscila entre los 18 y los 27 años y el año de egreso del secundario, entre 1994 y 2005.

Los datos se recogieron utilizando una encuesta con preguntas abiertas, cerradas y semiestructuradas destinadas a relevar las representaciones que los estudiantes tienen sobre la lectura y la escritura académica y, a su vez, detectar las concepciones sobre las tareas, sus intereses, actitudes y experiencias. Por último, se optó por solicitar una tarea escrita que consistió en elaborar un texto narrativo en el cual relataran su historia 
personal de escritura. En este trabajo sólo analizaremos los resultados de las encuestas de los alumnos de primer año correspondiente a la comisión Lenguas Extranjeras.

\section{Interpretación de los datos: análisis cualitativo}

Los materiales analizados de los alumnos de primer año de Lenguas Extranjeras (Italiano, Francés Portugués, Alemán) nos ofrecen información acerca de:

a. Las representaciones sobre la escritura académica.

b. Las representaciones sociales de la lectura.

A su vez, las representaciones se estructuran en torno a los siguientes principios de organización:

- Concepto de escritura.

- Imagen de sí mismo como escritor.

- Conocimiento sobre el propio proceso de producción.

- La lectura en el nivel superior.

Debemos destacar que, si bien el análisis de este trabajo se centra en una sola de las comisiones encuestadas de primer año de la materia Lengua Castellana I, podemos afirmar que los resultados de las demás comisiones de primer año pertenecientes al idioma Inglés son similares.

En cuanto al concepto de escritura, la mayoría de los encuestados piensa que "escribir bien" es saber expresarse y escribir textos cohesivos y coherentes:

- Escribir bien es expresar una idea, un sentimiento. (inf. 20)

- Porque la escritura es una forma de expresión importante y está presente en la vida cotidiana. (inf. 9)

- La escritura es el reflejo de la expresión. Si hablo bien escribo bien. (inf. 12)

- Para expresar correctamente lo que se quiere comunicar. (inf. 4)
En cuanto a los resultados de las encuestas asociados a la idea de los estudiantes sobre los aspectos que encontraron difíciles de escribir fueron:

- E1 80\% de los alumnos encuestados considera que escribir bien es "escribir sin errores de ortografía" y que "para escribir bien es necesario aprender las reglas de ortografía".

- Escribir bien es escribir sin errores de ortografía y prestando atención a la coherencia y cohesión. (inf. 1)

- Escribir sin errores ortográficos. y con una gramática correcta. (inf. 11)

- Escribir claro, que se entienda, sin errores de ortografía, con palabras tirando a cultas o poéticas, sin usar lunfardos y buen uso de las palabras.(inf. 6)

- Escribir bien es tener como base las reglas ortográficas, la gramática y/o la composición de palabras, vocabulario. (inf. 8)

Si el problema de la escritura fuera solamente lo expuesto, bastaría con memorizar las reglas ortográficas, pero esto no es suficiente para producir un texto adecuado a una situación comunicativa específica. El conocimiento de las normas gramaticales y ortográficas es útil, pues facilita el proceso de escritura; pero son tantas las dificultades a las que se enfrentan nuestros alumnos que esto les impide imaginar otras cuestiones conceptuales y estructurales relativas a la escritura, como la de los géneros, variedades, registros y destinatario, entre otras.

$\mathrm{El}$ análisis de las respuestas revela que parte del grupo no reconoce la escritura como un proceso cognitivo y dialéctico que está relacionado con la "transformación del conocimiento" (Beretier y Scardamalia, 1987). Escribir no es sólo usar adecuadamente las normas ortográficas y gramaticales o expresarse correctamente o, como lo afirma Paula Carlino (2005) escribir no sólo es un modo de expresar lo que se sabe sino de elaborarlo y no es un canal neutro sino sujeto a convenciones particulares de cada dominio.

En cuanto a la imagen que tienen de sí mismos como escritores, las encuestas muestran que el $71 \%$ de los estudiantes admite que les agrada 
escribir y el $88 \%$ que lo hacen porque les inculcaron el hábito:

- Me agrada escribir porque puedo volcar en un texto lo que yo siento e imagino. Me gusta jugar con la creatividad. (inf. 18)

- Me agrada escribir porque es un modo de dejar plasmado lo que pienso. (inf. 5)

- Porque siento cosas que no quiero olvidar. (inf. 12)

- Porque es un medio para desahogarme. (inf. 3)

- Porque es liberador para mi mente. (inf. 9)

- Hago rimas cuando me siento sola. (inf. 6)

- Me agrada escribir porque me siento libre de expresarme, tal vez, no como la sociedad espera y obliga a que lo haga, sino de manera personal. (inf. 22)

Paradójicamente, un grupo utilizó la escritura para admitir que no lès agrada escribir porque no saben hacerlo. Esto puede ser entendido, por un lado, porque los usos de la escritura que hacen en la universidad no son considerados como tal y, por el otro, por la idea de que la escritura está reservada a la inspiración y que los textos que se escriben están relacionados con la ficción literaria.

- No me gusta escribir. Nunca lo hice y no sé hacerlo. (inf. 15)

- No me agrada escribir porque no soy buena escritora. (inf. 4)

- No me gusta escribir. No soy creativa ni tengo imaginación. Me cuesta seleccionar las palabras que más se adecúen. (inf. 6)

- Creo que no tengo los elementos necesarios para poder escribir. A veces escribo pequeñas cosas pero no hago que otros las lean. (inf. 25)

Sólo el 4\% de los encuestados admite que les agrada escribir porque les permite aprender. Esto demuestra que la mayoría de los alumnos no asocia la escritura académica como herramienta para generar y modificar el conocimiento, es decir como herramienta epistémica. Además, subyace la concepción, en la mayoría de las respuestas, de la escritura como algo personal, íntimo y sólo como un canal por el cual se transmiten sentimientos.

Otro de los aspectos que se indagó con las encuestas es la representación que tenían los estudiantes acerca de su proceso cognitivo al producir un texto y en qué medida son conscientes de ello y pueden explicarlo. Para esto, se les preguntó si conocían las operaciones mentales que realizan al escribir; a lo cual un $70 \%$ respondió que no y el resto no contestó.

En cuanto a la representación que tenían sobre los procesos de escritura, ésta fue obtenida de las respuestas a la pregunta "cuando ud. escribe, ¿qué tareas realiza?" De los comentarios se extrae que sólo consideran como tareas de escritura la revisión del texto, la corrección y la reescritura. Nadie mostró la necesidad ni las ventajas de planificar, ni de considerar la organización de la información, ni la situación comunicativa, ni la audiencia, ni la situación discursiva; es decir

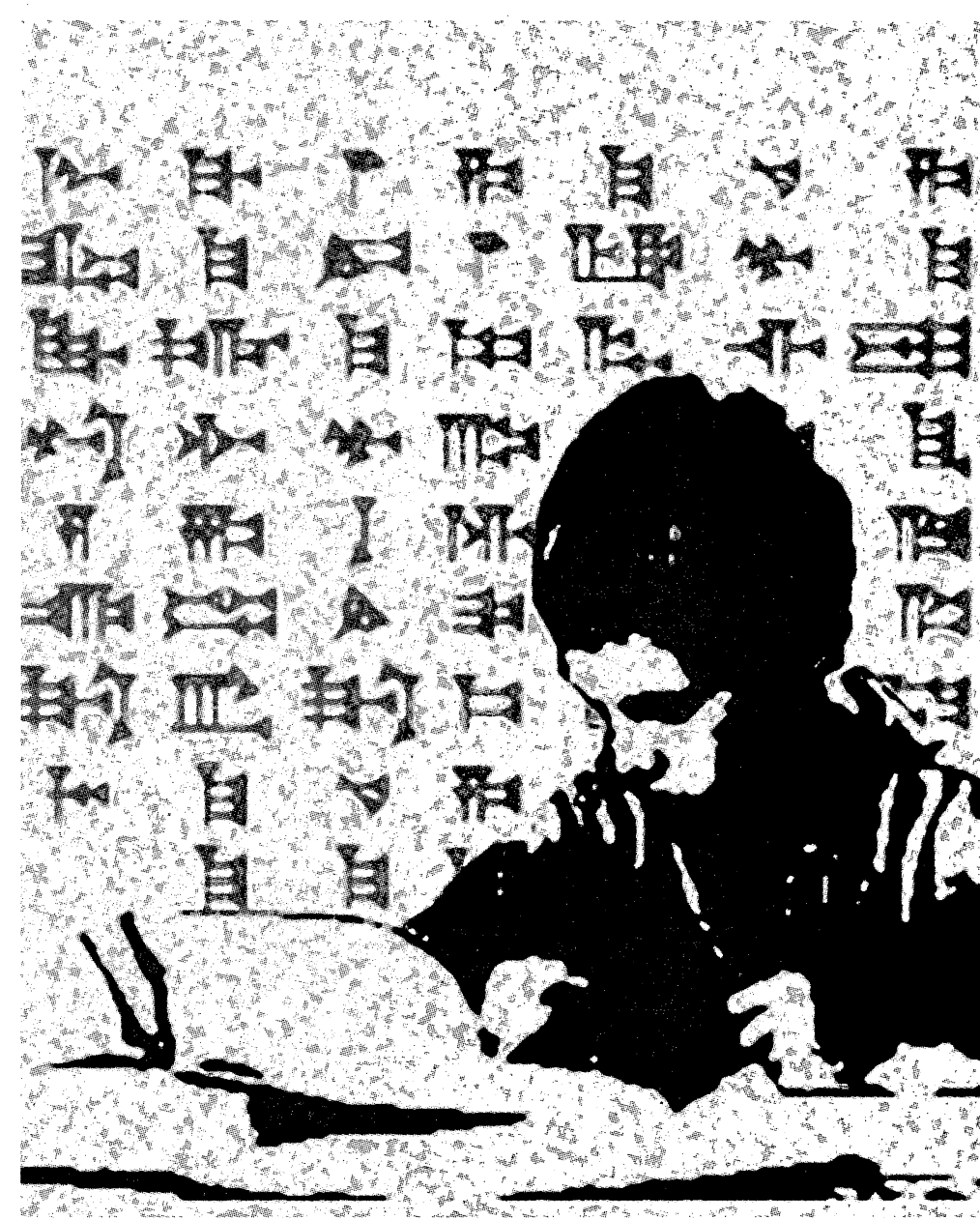


que no pudieron explicar el proceso de la escritura de una manera compleja como se espera de estudiantes universitarios. Esto nos lleva a concluir que los alumnos no son conscientes de sus propios procesos y que no consideran la escritura como un proceso dialéctico en el que se deben resolver las exigencias de una situación comunicativa (Castelló Badia, 2000).

Interrogados sobre qué tipos de textos escriben en español para el ámbito académico, contestaron: exámenes escritos, apuntes y notas de clase, resúmenes y síntesis. Esto nos muestra que la escritura está marcada por la pertenencia al ámbito educativo, que desconocen su función epistémica, es decir, que sirve como herramienta cognitiva para organizar lo que pueden pensar sobre un tema (Carlino, 2005), y que los jóvenes tienen una concepción instrumental de la-misma.

Les preguntamos qué lecturàs realizan habitualmente en la carrera y en otros espacios sociales. La mayoría del grupo reconoció que lee textos literarios -novelas, cuentos, poesía- y también libros de información general. En tercer término consideran la lectura de los textos académicos, entendidos éstos como aquellos que se usan para aprender en la universidad. Sin embargo las mayores dificultades se encuentran en las prácticas de textos destinados al estudio.

\section{Los malos lectores, al no tener una idea clara de la finalidad de la lectura, tampoco sienten la necesidad de cuestionarse si su modo de leer es el adecuado.}

- Me enriquezco. Me relajo. (inf. 12)

- Me gusta leer sobre todo textos literarios porque es una forma de entretenerme mucho más estimulante que la televisión. (inf: 8)

- Porque me divierto, paso un buen rato (la mayoría de las veces) y puedo escapar -por así decirlo- de este mundo con sus problemas y con los de mi vida, de mis preocupaciones, etc. (inf. 6)

- Porque es posible crear, imaginar, relajarse y disfrutar del placer que da la lectura. (inf. 4)
- Porque generalmente leo sobre temas que me interesan, y en los momentos libres es un método de distracción. (inf. 9)

Las Rs que tienen de la lectura es que ésta es una práctica que los rèlaja y los entretiene y en menor medida que es para aprender. Esta valoración de la lectura como algo que no demanda esfuerzo y que por lo tanto atrae como objeto de placer nos está indicando que la representación social que los alumnos tienen de las prácticas de lectura es muy diferente a lo esperado en los ámbitos académicos y esto puede incidir negativamente en el tipo de lectura que deben realizar. Como afirma Burón "los malos lectores, al no tener una idea clara de la finalidad de la lectura, tampoco sienten la necésidad de cuestionarse si su modo de leer es el adecuado [...] leen siempre igual, sea cual sea el fin y el tipo de lectura que hagan. Leen lo mismo para preparar un examen que para pasar el rato [...]" (Burón, 1996: 37).

\section{Conclusiones}

El análisis de las respuestas arroja las siguientes consideraciones:

Las representaciones de la escritura y de la lectura encierran una idea de la composición $y$ de la figura del escritor como medio para expresar sentimientos y como sujetos a la inspiración y la creatividad, lo que anula la concepción de la escritura como un proceso cognitivo, como práctica social. Es decir, tienen una concepción "idílica", lo que los lleva a escribir ficción para el deleite personal. Tampoco señalan que la escritura es una herramienta para construir y organizar el pensamiento; un pequeño grupo afirma que escribe para aprender; no reconocen la necesidad de identificar las características de los géneros discursivos como modo de encarar las prácticas de lectura y escritura universitarias. Desconocen cómo construir el rol del enunciador que deben asumir al producir un texto y no mencionan al destinatario explícito de los escritos.

En las prácticas de lectura hay una tendencia hacia la lectura de evasión y de entretenimiento y creemos que esto sucede porque los estudiantes reproducen las formas en que han 
leído en la escuela primaria y secundaria, centradas específicamente en textos literarios.

Quedan varias preguntas para responder acerca de las concepciones de la lectura y de la escritura, especialmente, ¿cómo se puede enseñar a producir textos y controlar el proceso de producción para que nuestros alumnos no fracasen en las tareas académicas?, por eso creemos que lòs docentes deben ocuparse de promover el desarrollo de las destrezas de la lectura y la escritura en los estudiantes para que puedan transferirlas a sus prácticas. $O$

\section{Bibliografía}

Acevedo, V. (2006), "Representaciones sociales de la escritura", en de Rúffolo, A. y Gómez, P. (coords.), Imaginario, representaciones sociales de identidad en la comunicación, Tucumán, Facultad de Filosofía y Letras, Universidad Nacional de Tucumán.

Ballesteros, L. A.; Reguera, A. y Sosa de Montyn, S. (2006), "Historias de escritura de estudiantes universitarios: la construcción de sí como escritor", ponencia presentada en las Jornadas de Lectura y Escritura del Litoral, Santa Fe, Argentina.

Burón Orejas, J. (1996), Enseñar a aprender. Introducción a la metacognición, Bilbao, Mensajero.

Carlino, P. (2005), Escribir, leer y aprender en la universidad. Una introducción a la alfabeti- zación acádémica, Buenos Aires, Fondo de Cultura Económica.

Castelló Badia, M. (2000), "Los conceptos de los estudiantes sobre la escritura académica”, en Miliam, M. y Camps, A., El papel de la actividad metalingüistica en el aprendizaje de la escritura, Rosario, Homo Sapiens Ediciones.

Jodelet, D. (1993), “La representación social: fenómeno, concepto y teoría", en Moscovici, S., Psicología social II. Pensamiento y vida social. Psicología social y problemas sociales, cognición y desarrollo bumano, Barcelona; Paidós.

Marinkovich Ravena, J. (1999, diciembre), "Módulos de producción de textos en el aula" en Lingüistica en el aula, año 3, núm. 3, Córdoba, Comunicarte, pp. 31-39.

Mato, D. (1999), Teoría politica de la construcción de identidades y diferencias en América Latina y el Caribe, Venezuela, unesco-Nueva Sociedad.

Miliam, M. y Camps, A. (2000), El papel de la actividad metalingüistica en el aprendizaje de la escritura, Rosario, Homo Sapiens Ediciones.

Moscovici, S. (1993), Psicología social II. Pensamiento y vida social. Psicología social y problemas sociales, cognición y desarrollo humano, Barcelona, Paidós.

Narvaja de Arnoux, E. et al. (2002), La lectura y la escritura en la universidad, Buenos Aires, Eudeba. 